\title{
Research on the Innovation of Supply Chain Financial Operation mode in the Pharmaceutical Circulation Field---Taking the Accounts Receivable Securitization as an Example
}

\author{
Kong Yan ${ }^{1}$, Wang Yanna ${ }^{1, *}$ \\ ${ }^{1}$ School of Economics and Trade, Guangzhou Xinhua University, Guangzhou, China
}

\begin{abstract}
In recent years, the scale of China's pharmaceutical circulation market has continued to expand, and the government has issued relevant policies to regulate the market. For example, the implementation of two-vote system has led to the increase of accounts receivable of pharmaceutical circulation enterprises year by year with a decrease of accounts receivable turnover rate and an increasing pressure of capital turnover. The enterprise accounts receivable securitization is an important way for enterprises to broaden financing channels, reduce financing costs, revitalize existing assets and improve the efficiency of asset use, while the securitization of statement type assets is the only standardized financial tool to reduce the leverage ratio of enterprises and realize financial optimization. Asset securitization can relieve the pressure of capital turnover and reduce the cost of financing. The case analysis part of this paper analyzes the factors that promote the financial innovation of enterprise's supply chain from the macro and micro perspectives. And also from the perspective of the capital demand of upstream and downstream enterprises, this part analyzes the motivation of developing supply chain financial innovation. the innovation of supply chain financial operation mode.
\end{abstract}

\section{Introduction}

The report of the 19th National Congress of the Communist Party of China proposed to cultivate new growth points and form new momentum in the fields of modern supply chain, which means that accelerating supply chain innovation and building a modern supply chain has become an important part of deepening supply side structural reform and building a modern economic system. At present, China, as the second largest pharmaceutical market in the world, will increase with the expansion of the global market in the future. Therefore, the demand for financing in the supply chain of the pharmaceutical circulation market is also increasing. The focus of supply chain research is gradually shifting to the innovation level of supply chain finance to improve the efficiency of capital flow.

On January 9, 2017, the National Health and Family Planning Commission issued the article Suggestions and Opinions on the Implementation of the Two-vote System in Drug Procurement of Public Medical Institutions (Trial). The implementation of the two-vote system greatly reduced the links of drug circulation and drug prices, but also brought challenges to the upstream and downstream industrial chain, and gave birth to a trillionlevel financial market of drug circulation supply chain.

The implementation of the two-vote system reform aims to effectively integrate the scattered resources at both upstream and downstream ends. From the supply chain model of the pharmaceutical industry, we can see that the pharmaceutical industry is in the core position of the supply chain. Besides, the strong position of the downstream hospitals coupled with the general credit sales mode and the long payback period of the industry make the pharmaceutical circulation enterprises in a weak position facing huge capital chain pressure. The capital problem not only restricts the normal operation of enterprises, but also restricts the overall development, transformation and upgrading of the industry. From the perspective of financing methods, circulation enterprises are still dominated by short-term debt, and the scale of debt is rising rapidly. Because drug circulation business does not need a lot of fixed asset investment, many circulation enterprises have a high level of assets and liabilities, and face greater debt repayment pressure, so it is imperative to find new financing methods. As an efficient direct financing tool, asset securitization can solve the pain points of pharmaceutical circulation enterprises, revitalize trillions of pharmaceutical circulation upstream and downstream accounts receivables, and create a new way of financing for circulation enterprises. The continuous innovation of supply chain finance brings the corresponding development opportunities to the participants of supply chain.

\footnotetext{
* Corresponding author: 859008061@qq.com
} 


\section{Literature Review}

\subsection{Motivation of Asset Securitization}

Greenbaum and Thakor (1987), Hess and Smith (1988) and other scholars put forward the view that asset securitization is innovative and low-cost for financing ${ }^{[1]}$; On this basis, stvene L. Schwarcz (1994) put forward the theory of financial alchemy. He believed that asset securitization can effectively reduce and save the financing cost of enterprises, enabling enterprises to get more benefits ${ }^{[1]}$. Monica (2011) believes that the main reason for enterprises to carry out asset securitization is to convert illiquid assets into highly liquid ones that can be circulated in the market, so as to improve the asset utilization efficiency of enterprises. After studying the operation of some small and medium-sized enterprises ${ }^{[2]}$, Antoni and Kim (2012) found that they had a large amount of accounts receivable but lacked capital. The use of equity or debt financing will bring high financing costs to enterprises. Thus, enterprises will tend to use asset securitization financing, which can improve the use efficiency of assets and reduce the financing costs of enterprises $^{[3]}$.

\subsection{Effect of Asset Securitization}

He Zhen (2016) found that after the implementation of accounts receivable securitization, the capital structure of listed companies has been improved accordingly. Besides, the capital obtained by enterprises after revitalizing accounts receivable can be used for research and development ${ }^{[4]}$. Sanket (2002) proposed that the accounts receivable securitization is a kind of off balance sheet financing. By comparing the financial indicators before and after financing, he found that this comparison was conducive to the improvement and optimization of the capital structure of enterprises ${ }^{[5]}$. Zhao Shenglai and Chen Junfang (2006) studied both the basic and core principles of asset securitization, and found that the capital structure of enterprises has been improved accordingly after asset securitization. Yu Chunyan (2016) and others, after studying the design of accounts receivable securitization launched by Bank of Tianjin for small and medium-sized enterprises, believe that for SMEs with high-quality accounts receivable, accounts receivable securitization can not only revitalize the stock assets, but also solve the financing difficulties of them and reduce their financing costs ${ }^{[4]}$.

\subsection{Supply Chain Finance of Pharmaceutical Circulation Enterprises}

From the perspective of commercial banks, Cao Qingzhong (2012) made a comparison of traditional financing and supply chain financing, and thought that the latter was more suitable for SMEs in the pharmaceutical industry. Tian Yuan (2015) made a comprehensive analysis on the development of supply chain financial services for pharmaceutical circulation enterprises, and analyzed the feasibility of the development of pharmaceutical supply chain finance according to their characteristics and other factors. He believed that supply chain finance solved the problem of upstream and downstream financing, and can effectively achieve resource allocation by combining with Internet technology ${ }^{[6]}$. Gu Yeqiang and Liu Yannian (2018) believed that the two-vote system reform increased the financing demand of circulation enterprises, and at the same time, credit resources were also concentrated in large pharmaceutical circulation enterprises. Banks should take pharmaceutical circulation enterprises as the core, provide financing for upstream and downstream enterprises, promote accounts receivable financing mode, and develop online supply chain financing, so as to achieve a win-win situation between banks and enterprises. Ulrich Franke (2005) pointed out that assetbacked securities could be used, especially in medical financing. It is suggested that we can follow the example of the United States to package medical accounts receivable as basic assets ${ }^{[7]}$.

From the above literature, it can be seen that scholars at home and abroad generally agree that through carrying out asset securitization and revitalizing the existing assets, enterprises can obtain sufficient cash to alleviate the pressure of capital turnover ${ }^{[8]}$; At the same time, the financing cost of asset securitization is lower, thus the accounts receivable can be securitized as basic assets. The research of scholars shows that the supply chain financial innovation is an effective means to break the capital bottleneck. This paper will learn from the previous research results on the motivation, effect and supply chain financial model of asset securitization, and analyze the reasons for the increased capital turnover pressure of pharmaceutical circulation enterprises after the implementation of the two-vote system. Combing with the particularity of the accounts receivable securitization of pharmaceutical circulation enterprises (for example, the bottom debtors of the developed products are secondary or above public hospitals), due to the problems in purchasing and paying habits, this paper puts forward some financing suggestions for the accounts receivable securitization of pharmaceutical circulation enterprises.

\section{Analysis of Financial Pressure of Pharmaceutical Circulation Enterprises}

The traditional supply chain finance of pharmaceutical circulation enterprises is based on the pharmaceutical circulation enterprises and their business contacts with upstream and downstream enterprises. It provides the upstream and downstream enterprises with such supply chain financial services as accounts receivable financing, order financing, inventory financing, etc. (Figure 1). The traditional supply chain finance of pharmaceutical circulation enterprises transforms the uncontrollable risk of a single enterprise into the controllable risk of the whole enterprise in the supply chain by sharing the accurate and transparent information in the supply chain, so as to realize the transmission of credit and reduce the financing cost of the whole supply chain. In the supply 
chain finance of pharmaceutical circulation enterprises, pharmaceutical circulation enterprises have two roles: core enterprises and logistics enterprises. There are three main modes of supply chain finance of pharmaceutical circulation enterprises, namely confirmed warehouse mode of warehouse receipt pledge financing, financing warehouse mode of inventory pledge financing and accounts receivable pledge financing.

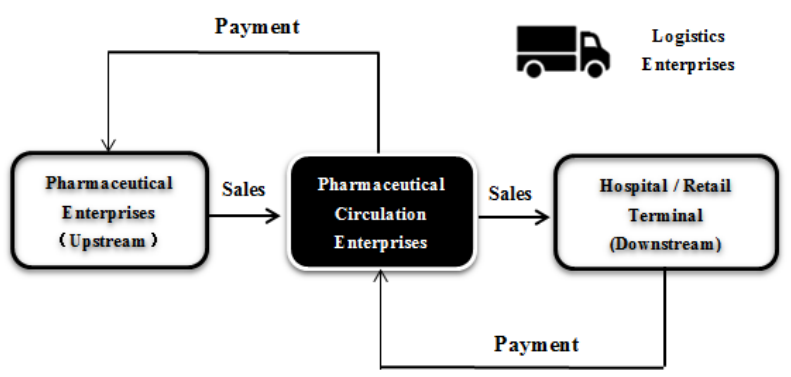

Fig. 1. Traditional Supply Chain of Financial Model

Before the implementation of two-vote system, the mode of medicine circulation goes as drug company $\rightarrow$ product agent (multi-level) $\rightarrow$ medicine distributor $\rightarrow$ hospital $\rightarrow$ patient. After the implementation of this system, the mode is drug company $\rightarrow$ drug distributor $\rightarrow$ hospital $\rightarrow$ patient. Intuitively, the two-vote system reduces the agent in the mode. In the traditional hospital circulation mode, the advance payment is undertaken by agents. After the implementation of the two-vote system, a large number of agents and other intermediate parts withdraw from this mode, and the pharmaceutical distributors assume the function of paying for pharmaceutical production enterprises. But in the actual operation process, without the product agents to help break down the capital chain, the pharmaceutical distributors in the middle link are facing huge financial pressure.

In addition, the long collection time of money for the downstream hospitals is also one of the reasons for the greater pressure on the cost of capital of pharmaceutical distributors. Nationwide, the credit period of hospitals ranges from 45 days to three months, which deepens the problem of cash flow of pharmaceutical distributors. The larger the scale of hospital credit, the greater the pressure of financial expenses. In the past, in order to cope with this kind of financial pressure, the upstream supplier association cooperated with commercial banks to carry out accounts receivable factoring business. However, this business form based on supply chain finance 1.0 is easy to generate bad debts and risks due to asymmetric and incomplete information (such as inaccurate and incomplete supply information), as well as the moral hazard caused by a lack of credit (such as false bills and business).

Even in the state of factoring business, as the downstream medical institutions need confirmation, there are also potential risks due to information asymmetry and human confirmation error. Under the two-vote system, although the links of the pharmaceutical circulation supply chain are reduced and the tax is more compliant, the cost and capital pressure caused by hospital accounting period, tax, and doctor rebate have not been fundamentally solved. The system only makes the capital pressure of the pharmaceutical industry chain concentrate in one link, and increases the tax pressure. This situation is not conducive to the stable and sustainable development of the pharmaceutical industry, as well as to the normal business operation of the relevant stakeholders in the industry. It is this situation that makes the innovation of supply chain financial operation mode become an important strategic means to optimize the cash flow in the pharmaceutical circulation and promote the common development of the industry.

\section{Innovation of Process Design of Asset Securitization}

\subsection{Analysis on the motivation of innovation in supply chain finance}

According to the analysis in the third part, it can be seen that the strong downstream main hospital will require upstream enterprises to give large commercial credit lines or a long period of time to transfer the pressure of the capital chain to the upstream, making the enterprises bear huge debt end pressure. The amount of accounts receivable and the length of the account period are the important factors affecting the capital arrangement of the enterprise. The receivables formed in the stage of sales collection are assets in the form of creditor's rights that enterprises can use as a pledge to obtain financial support.

After the implementation of the two-vote system, the distribution pattern of drugs has been greatly adjusted. The pharmaceutical manufacturers choose large-scale pharmaceutical circulation enterprises with full network system, good quality and credibility and strong distribution capacity to carry out drug distribution. Small dealers, secondary or above agents have been merged or eliminated by large commercial companies, which has improved the market concentration and scale development. With less fixed assets, the drug circulation business does not need a large amount of fixed assets. Thus it is imperative for many circulation enterprises in high level of assets and liabilities and great debts pressure to find new financing methods. The large pharmaceutical circulation enterprises having good quality receivables is easy to be recognized by market investors. It can realize the asset securitization of accounts receivable and withdraw capital in advance to relieve the pressure of capital chain.

\subsection{Innovative design of process}

The innovation of the process is mainly reflected in the introduction of difference payment promisor on the basis of the original model, extending the supply chain finance form from internal mutual guarantee to internal and external two-way guarantee, extending the length of the 
supply chain service, and building a "closed loop" ecosystem of supply chain finance.

\subsubsection{Basic Assets}

To determine the standard of qualified basic assets, screen the qualified basic assets (based on the accounts receivable formed by drug sales, medical device sales and other businesses for public secondary and above hospitals), and construct the asset pool with accounts receivable as the initial basic assets. The basic assets shall be transferred from the original owner to the manager on the date of the establishment of the special plan.

\subsubsection{Participants}

Sponsor: people proposing asset securitization, that are the pharmaceutical circulation enterprise and the original equity person of the receivables.

Issuer: act as an intermediary in asset securitization, that is the securities asset management company. Firstly, the company buys the assets sold by the sponsor, and then find qualified investors to sell according to the personalized characteristics of the assets (such as asset size and cash flow).

Rating agency: the credit rating company, an organization that ratings the high-grade shares of issuers and issued securities.

Investors: institutional investors. At present, the asset securitization in China mostly adopts private equity to raise money.

Service provider: pharmaceutical circulation enterprise, an important part sharing responsibility in the process of asset securitization.

In addition, legal counsel, underwriter, capital custodian and clearing institution are also very important participants in the process of asset securitization.

\subsubsection{Transaction Process}

The specific transaction structure is shown in Figure 2.

(1) Asset management companies issue asset-backed securities to qualified institutional investors and set up special plans to raise money.

(2) After a raise of required capital, it will be used to purchase the corresponding basic assets from the pharmaceutical circulation enterprises, and pay the money for purchasing the basic assets to the pharmaceutical circulation enterprises at one time.

(3) During the duration of the special plan, the cash from the hospital will be transferred into the designated escrow bank account according to the contract. The escrow bank will distribute the principal and interest of the cash among the asset securitization products at all levels according to the distribution instructions of the asset manager.

(4) In terms of external credit enhancement, the investment company acts as the difference payment promisor of the special plan, promising that if the return capital of the special plan cannot cover the principal and interest of the issued priority securities, the investment company will make up the difference to ensure the investment rights and interests of investors.

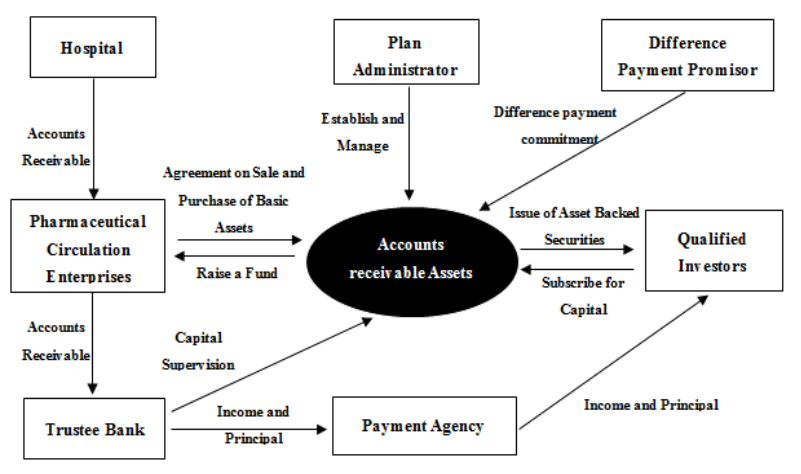

Fig. 2. Transaction Structure of Accounts Receivable Asset Support Special Plan

\section{Conclusion and Suggestions}

This paper chooses pharmaceutical circulation enterprises as a case to discuss the innovation mode of supply chain finance. The main conclusions are as follows:

\subsection{Authenticity Check of Basic Assets}

Since the hospital takes a superior place in the industrial chain, there are many cases when the creditor's rights of receivables have not formed a written contract or documents confirmed by both parties. In case of no special written contract, it can be confirmed according to the inspection of the delivery order, delivery note or accompanying goods peer document and other written confirmation documents related to the target basic assets and the explanation of pharmaceutical circulation enterprises. The premise of successful issuance of asset securitization products is to ensure the high quality of basic assets. If there are defects, re-transfer or commercial disputes, the receivables may cause losses of basic assets.

\subsection{Arrangement of Product Term}

Most of the underlying transactions are in spiral process based on the long-term cooperative relationship between pharmaceutical circulation enterprises and hospitals. Thus, there exists a problem that there is no written agreement on a clear repayment period. In this case, the determination of cash flow return in asset securitization is an important issue. Generally speaking, pharmaceutical circulation enterprises will give different credit lines and credit periods according to the historical transaction situation of each buyer. The expected payment date of each account receivable is predicted by the invoice date, delivery date and credit accounting period according to the actual situation. At the same time, due to the short accounting period, most of the products are designed to buy circularly, and the interest is 
distributed during the circulation period, and the principal passes through during the amortization period.

\subsection{Arrangement of Credit Enhancement Measures}

In terms of internal credit enhancement, like ordinary ABS, there are structural stratification, coverage of excess interest margin, and the setting of accelerated liquidation, default event and power improvement event notification mechanism. As for external credit enhancement, we can choose whether to be paid or guaranteed by the original equity holders or other parties (mostly shareholders) according to the needs of the statement.

\subsection{The Support of Information System of Original Owner}

Information system is an important technical support system for the management of modern pharmaceutical logistics enterprises. With the expansion of the original owners' business scale and the deepening of cross regional business development, the original owners put forward higher requirements for the construction of information system in the aspects of business concentration and standardized operation, collaborative management information, auxiliary financial accounting, and improvement of logistics management. A perfect system also facilitates the development of asset securitization business, such as the verification of underlying relevant materials, hospital historical collection records, credit situation, credit period prediction. Managers should also conduct full due diligence on the effectiveness, reliability and stability of the information system.

\section{Acknowledgment}

The authors are grateful for the financial support of the Youth Innovation Project of Key Platform of Colleges and Universities in Guangdong Province (2016WQNCX188) ; and the Project of Teaching Team of Internet Finance Course (2019T002) in Xinhua College of Sun Yat-sen University ; the 2016 Department of Education of Guangdong Province Key Discipline "Public Administration" research project;

\section{References}

1. Lakshman L.A. Asset Securitization and Structured Financing:Future Prospects and Challengesfor Emerging Market Countries, IMF Working Paper, 2001.

2. Monica N. Outlook for The Market [J]. Financial Market Trends, 2011(1):259-278.

3. Antonio V, Kim S. Policy-based and market alternatives [M]. America: East Asian Lessons for Latin America and the Cariwean, 2012(6):163-182.
4. Yu C.Y, Chen Z.C, Ning J.F. Stock revitalizing Technology: Securitization of accounts receivable [J]. Financial Market Research, 2016(4):43-49.

5. Sanket K. Receivables Securitization The Nonfinancial Firm [J]. The Wharton School University of Pennsylvania, 2002, (6):73-76.

6. Han T.T. Research on the securitization of accounts receivable of small and medium sized enterprises under the background of Supply Chain Finance [J]. Times Finance, 2015(12):117+119.

7. Lacobucci E.M, Ulrich F, Winter R.A. Asset securitization and asymmetric information [J]. Journal of Legal Studies, 34(2005):161-207

8. Chi J.H. Research on risk prevention of asset securitization financing of listed enterprises in China [J]. Friends of Accounting, 2007(1):22-23 